\title{
Balkanologie
}

Balkanologie Revue d'études pluridisciplinaires

Vol. XI, $n^{\circ}$ 1-2 | 2008

Volume XI Numéro 1-2

\section{La Serbie post-Milošević : introduction}

\section{Yves Tomić}

\section{(2) OpenEdition}

Journals

Édition électronique

URL : http://journals.openedition.org/balkanologie/1583

DOI : 10.4000/balkanologie.1583

ISSN : 1965-0582

\section{Éditeur}

Association française d'études sur les Balkans (Afebalk)

\section{Référence électronique}

Yves Tomić, «La Serbie post-Milošević : introduction », Balkanologie [En ligne], Vol. XI, n 1-2 | 2008, mis en ligne le 31 décembre 2008, consulté le 17 décembre 2020. URL : http://

journals.openedition.org/balkanologie/1583 ; DOI : https://doi.org/10.4000/balkanologie.1583

Ce document a été généré automatiquement le 17 décembre 2020.

(c) Tous droits réservés 


\title{
La Serbie post-Milošević : introduction
}

\author{
Yves Tomić
}

1 Ce dossier réunit la plupart des contributions à la demi-journée d'études organisée par l'Association française d'études sur les Balkans le 8 février 2008 et intitulée «La Serbie post-Milošević : continuités/discontinuités ».

2 Cette manifestation a été organisée afin d'évaluer les changements intervenus en Serbie depuis la chute de Slobodan Milošević le 5 octobre 2000. En effet, le retrait de la vie politique du président yougoslave a ouvert la voie à la démocratisation de la Serbie. Pour autant, l'idéologie dominante des années 1990, le nationalisme et la défense des intérêts nationaux serbes ont-ils été remis en question ? Dans quelle mesure la Serbie at-elle rompu avec son passé immédiat? Dans quelle mesure existe-t-il un danger de remise en cause des acquis démocratiques? Les forces nationalistes et autoritaires (en premier lieu le Parti radical serbe et le Parti socialiste de Serbie) peuvent-elles remettre en cause l'évolution démocratique que connaît la Serbie depuis l'automne 2000 ? Les questions territoriales, liées à la résolution du statut du Kosovo en particulier, aurontelles des conséquences sur la vie politique du pays?

Les services de renseignements, autrefois principaux rouages du pouvoir du président yougoslave, sont-ils complètement sous le contrôle du pouvoir politique ? D'un point de vue systémique, la Serbie est-elle sortie d'un système économique et social où l'Etat est omniprésent? Sur le plan idéologique, quelles sont les éventuelles continuités avec le précédent régime?

4 Les différentes interventions de la demi-journée d'études n'auront pas permis de répondre à l'ensemble de ces questions. En effet, les réformes économiques et sociales n'ont pas été abordées et certains aspects de la transition démocratique n'ont été traités que superficiellement ${ }^{1}$. Parmi les éléments significatifs de la transition figurent la question de la réforme des structures de sécurité et surtout de l'agence de renseignement, dénommée aujourd'hui BIA. Le Service de sécurité d'Etat (Služba državne bezbednosti, SDB) a joué un rôle important dans l'exercice du pouvoir de Slobodan Milošević. Ce service n'a pas été purgé après les événements du 5 octobre 
2000 du fait du soutien apporté par Vojislav Koštunica à Radomir Marković, le chef du SDB qui a été maintenu dans ses fonctions jusqu'en janvier 2001. Ce dernier a eu tout le temps de faire détruire les dossiers compromettants. La création de l'Agence de sécurité et d'information (BIA) ayant succédé au SDB n'a pas apporté de modifications significatives quant à la transparence des activités de cette structure ${ }^{2}$. Cette dernière semblait ne pas être sous le contrôle complet des autorités politiques jusqu'au printemps 2008.

5 Si la transition démocratique a bien commencé au cours des années 1989-1990 avec l'introduction du pluralisme politique et le lancement de la privatisation des entreprises sociales, force est de constater que la transition a été bloquée, les autorités politiques serbes entravant l'alternance politique en ne reconnaissant pas la victoire de leurs opposants démocrates (crise de 1996-1997, élections de septembre 2000)․․ De même, le processus de privatisation a été stoppé au milieu des années 1990 et de nombreuses privatisations du début de la décennie ont été annulées. Le régime de Slobodan Milošević respectait certaines formes de la démocratie (élections pluralistes) mais les conditions de la démocratie n'étaient pas pour autant toute réunies (principaux médias .contrôlés par le pouvoir, etc.). Ce système peut être défini de régime hybride ou d'autoritarisme électoral (electoral authoritarianism) ${ }^{4}$.

6 L'article d'Ivana Spasić, sociologue, étudie la transition démocratique du point de vue des citoyens. Elle a participé à plusieurs enquêtes sociologiques entre 2002 et 2007 dans le but d'analyser les liens entre la vie quotidienne des citoyens et leurs perceptions des transformations politiques et sociales. A l'optimisme constaté en 2002 a succédé la déception en 2005 et 2007.

7 Srdjan Cvijic, observateur de la vie politique serbe, analyse les événements de la période 2000-2008. Il constate la prégnance du nationalisme dans la société serbe qu'il considère comme un obstacle à la consolidation de la démocratie. Néanmoins, il s'interroge dans quelle mesure le «système politique bloqué » du fait de l'exclusion du Parti radical serbe de l'exercice du pouvoir n'entraîne pas des conséquences négatives sur les institutions du pays (assemblée nationale, présidence). Néanmoins, depuis février 2008, la situation a sensiblement évolué puisque le Parti radical serbe a connu une scission importante avec le départ de son vice-président Tomislav Nikolić suivi par de nombreux cadres qui ont depuis fondé le Parti progressiste serbe (Srpska napredna stranka). L'article de Srdjan Cvijic n'en demeure pas moins utile puisqu'il pose la question de la tolérance des partis considérés comme intolérants et antidémocratiques.

Marlene Spoerri, doctorante au Département des études est-européennes de l'Université d'Amsterdam, s'interroge sur les pratiques démocratiques internes des partis politiques en Serbie. Dans quelle mesure les changements démocratiques depuis octobre 2000 ont-ils facilité la démocratisation des formations politiques serbes? L'auteur constate que ces dernières sont devenues paradoxalement moins démocratiques, ne contribuant pas ainsi à améliorer l'image de la classe politique serbe.

Barbara N. Wiesinger étudie l'extrême droite dans la Serbie d'aujourd'hui et plus particulièrement les groupes Srpski Sabor Dveri, Otačastveni Pokret Obraz, Krv i čast et Nacionalni stroj. L'auteur montre que les programmes de ces organisations sont très semblables: ils sont basés sur un nationalisme exacerbé reposant sur l'idée de la renaissance nationale et une remise en cause des institutions et des valeurs démocratiques. 
Enfin Adam Fagan et Mladen Ostojić étudient l'impact de l'intervention de l'Union européenne sur la société civile et la démocratisation de la société serbe.

De nombreux progrès ont été enregistrés depuis le 5 octobre 2000. La Serbie est désormais une "démocratie électorale " où les résultats des scrutins ne sont plus falsifiés. Néanmoins, des faiblesses structurelles existent toujours avec le maintien du domaine réservé de la sécurité d'Etat. En outre, le passé immédiat de la Serbie n'a pas été remis en question sérieusement, en particulier les crimes de masse commis au nom des Serbes, comme en témoignent les ouvrages scolaires et les débats entre hommes politiques et intellectuels. Le système électoral est loin d'être parfait puisqu'il lie davantage les représentants du peuple aux directions des différents partis plutôt qu'aux citoyens électeurs. Néanmoins, la Serbie a franchi en 2008 une étape importante dans le processus de consolidation de la démocratie avec la formation d'un gouvernement de coalition entre le Parti démocrate et le Parti socialiste de Serbie. En outre, le Parti radical serbe sort affaibli de la scission qu'il a subie en 2008. Aujourd'hui, le SRS n'attire plus que $10 \%$ des électeurs, tandis que le Parti progressiste serbe de Tomislav Nikolić bénéficie d'un score deux fois supérieur.

\section{NOTES}

1. A propos des réformes économiques et sociales, voir Zec (Miodrag), Cerović (Božidar), Kuda ide Srbija: ostvarenja $i$ dometi reformi, Beograd, Ekonomski fakultet u Beogradu, 2008, 301 p.; Reforme u Srbiji : dostignuća i izazovi, Beograd, Centar za liberalno-demokratske studije, 2008, 108 p. (consultable à l'adresse URL: http://www.clds.org.yu/newsite/Reforme u Srbiji dostignuca i izazovi-1.pdf). Il existe une version anglaise de cette étude : Reforms in Serbia: Achievements and Challenges, consultable à l'adresse : http://www.clds.org.yu/newsite/Reforme08-eng.pdf.

2. Voir Pavlović (Dušan), Antonić (Slobodan), Konsolidacija demokratskih ustanova u Srbiji posle 2000. godine, Beograd, Službeni glasnik, 2007, pp.124-140.

3. Lazić (Mladen), "Les obstacles sociaux et institutionnels au processus de transformation en Serbie ", Revue d'études comparatives Est-Ouest, volume 35, mars-juin 2004, n¹-2, pp. 17-34.

4. Voir Pavlović (Dušan), Antonić (Slobodan), Konsolidacija demokratskih ustanova u Srbiji posle 2000. godine, Beograd, Službeni glasnik, 2007, pp.78-82.

\section{INDEX}

Mots-clés : Transition démocratique

Index géographique : Serbie 